\title{
Asthma and Environmental Indicators: A Time-series Study
}

\author{
Amaury de Souza ${ }^{{ }^{*}}$, Alexandra Zampieri Kofanovski ${ }^{1}$, Ismail Sabbah ${ }^{2}$ and Débora A da Silva Santos ${ }^{3}$ \\ ${ }^{1}$ Institute of Physics, Federal University of South Mato Grosso, PO Box 549, 79070-900 Campo Grande, Mato Grosso do Sul, Brazil \\ ${ }^{2}$ Department of Natural Sciences, College of Health Sciences, the Public Authority for Applied Education and Training, Kuwait \\ ${ }^{3}$ Nursing Department, Federal University of Mato Grosso, Campus Rondonopolis, Brazil
}

*Corresponding author: de Souza Amaury, Institute of Physics, Federal University of South Mato Grosso, PO Box 549, 79070-900 Campo Grande, Mato Grosso do Sul, Brazil, Tel: +55 67 3345-7001; E-mail: amaury.de@uol.com.br

Received date: January 30, 2016; Accepted date: February 15, 2016; Published date: February 22, 2016

Copyright: ( 2016 de Souza A, et al. This is an open-access article distributed under the terms of the Creative Commons Attribution License, which permits unrestricted use, distribution, and reproduction in any medium, provided the original author and source are credited.

\begin{abstract}
Objective: To estimate the risk of ozone concentration and hospitalizations for asthma.

Method: This is an ecological time series, which included individuals from 0 to 10 years old who lived in Campo Grande, Mato Grosso do Sul (Brasil), from 2008 to 2010. The data on hospitalizations for asthma were obtained online from DATASUS website. Data from environment levels of ozone were obtained from Instituto de Física of UFMS and temperature and humidity from Centro de Monitoramento de Clima e Recursos Hídricos (CEMTEC). Gap designs were made from 0 to 6 days and analyzed by generalized additive Poisson's regression model and its $95 \%$ confidence intervals.
\end{abstract}

Results: There were 5850 admissions, presenting daily changes from 2 to 13 . The relative risks and their respective confidence intervals were obtained for each parameter: ozone-RR $0.9965(0.9467-1.0463)$; precipitation RR-0.9975 (0.9476-1.0474); RH RR-0.9948 (0.9450-1.0455); RR-speed winds 1.0036 (0.9535-1.0538) and RRtemperature $0.9679(0.9195-1.0163)$.

Conclusion: It was possible to identify association of ozone as in the same day of exposure as in the days ahead after the admissions. Thus, this study showed an association between ozone and hospitalizations for asthma in a medium-sized city.

Keywords: Asthma; Air Pollution; Epidemiology; Ozone

\section{Introduction}

The most susceptible groups to the adverse effects of climate/ pollution are children and elderly [1-3]. For children, the fact is due to greater exposure to pollutants, high ventilation time and high levels of physical activity [4]. Among the effects of chronic exposure to air pollution in children and teenagers, we can highlight decrease of development and pulmonary function, and increase in the number of episodes of respiratory diseases and hospital admissions $[5,6]$.

Air pollutants associated with outcomes such as chronic diseases in children and increases in the risk of death are mainly: particulate matter $\left(\mathrm{PM}_{10}\right)$, sulfur dioxide $\left(\mathrm{SO}_{2}\right)$ and ozone $\left(\mathrm{O}_{3}\right)$ [7]. Considering the evidence that shows the association between exposure to air pollutants and health conditions, the mechanisms by which these diseases are still caused are not well elucidated, but it is believed that the histological lesions caused by pollutants in the lung parenchyma may increase the harmful effects of viruses and/or allergens [8].

The exposure to $\mathrm{O}_{3}$, in turn, is associated with decreased lung function, increased reactivity and respiratory tract inflammation and impaired macrophage function [9]. It is believed that the adverse effects caused by exposure to environmental pollutants present a behavior lag (lag), which means that an individual exposed to a pollutant during a day may come forward with acute asthma attack a few days later $[2,3]$.
Asthma is chronic and genetic in nature and an environmental component, very common among children, it is mainly responsible for the prolonged impairment of health in developed countries and is highly prevalent in developing countries $[10,11]$. It is characterized by being a result of bronchial inflammation, with an exaggerated response of the lower respiratory tract and flow limitation in it [12]. This study aims to estimate the risk of association between exposure to air pollutants (ozone), climatic parameters and admissions for bronchial asthma in childhood, in Campo Grande-MS.

\section{Methods}

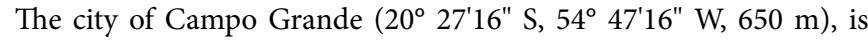
located on a plateau called Maracaju. Campo Grande is about $150 \mathrm{~km}$ from the beginning of the largest floodplain in the world, Pantanal Mato-Grossense (139 $111 \mathrm{~km}^{2}$ area). Campo Grande is located in a tropical region, so it presents predominantly warm climate throughout the year, with high levels of rainfall and high humidity. The annual period average temperature of the city is $23.5^{\circ} \mathrm{C}$, and the average rainfall is $1396 \mathrm{~mm}$, the air humidity has an average value of $71 \%$, but it varies between $64.7 \%$ and $79 \%$. The predominant wind direction is North quadrant (N), followed by Northeast (NE) and East (E) [13].

This is an ecological study of temporal series, in which were selected as admissions for bronchial asthma (ICD-10: J45) [9] in individuals $0-10$ years old in Campo Grande, in the period from 01/01/2008 to $31 / 12 / 2010$. The data obtained were from the website of the 
Department of Information and Informatics of the Unified Health System (DATASUS) [14]. In addition, environmental pollutant levels of data in its medium daily ozone, were obtained from the Instituto de Física of UFMS, which has the equipment needed to measure these levels. The temperature data, precipitation, wind speed and air relative humidity was obtained from Monitoring Centre for Climate and Water Resources (CEMTEC) of Mato Grosso do Sul.

The estimated risk for hospitalizations for asthma due to exposure to the pollutant was made by the use of Poisson's regression generalized additive model. In order to do that, the ozone data was always analyzed together with humidity and air temperature, and controlled by day of the week and seasonality.

Aiming to assess the impact of air pollution and climate on human health, it was used the generalized linear model (GLM) with Poisson's regression.

Poisson's regression model is a specific type of GLM, where the aim is to estimate $\beta \mathrm{i}$ regression coefficients of the following equation:

$$
\ln (\mu)=\beta_{0}+\beta_{1} X_{1}+\beta_{2} X_{2}+\ldots+\beta_{n} X_{n}
$$

$\mu$ is the dependent variable (number of admissions for respiratory diseases in Campo Grande), $\beta \mathrm{i}$ are the parameters to be studied and $\mathrm{Xi}$ are the independent variables.

In time-series studies of the impact of air pollution on human health using GLM with Poisson's regression, it is needed: concentration of the considered air pollutants; meteorological variables; health effects and some confounding factors. Data should be available for at least two years and separated by day. In epidemiological studies it is common to find relation between the concentration of air pollutants from one day to the health effects on the next day, two days later, even after a week or more. So researchers often adjust the model to different arrangements of the same database with lags. In time series studies, lags of one to seven days are often applied [15-18].

The relative risk (called ratio rate by statisticians) [19] is used to estimate the impact of air pollution on human health, performing some projections according to the concentration of pollutants. It is a measure of association between a particular factor X (for example, the concentration of air pollutants), and the risk of a given outcome $\mathrm{Y}$ (for example, the number of people with respiratory problems in a region) [20]. More specifically, the relative risk due to the level of a pollutant $x$ is defined by [21]:

$$
R R_{x}=\frac{E_{(Y / X)}}{E_{(Y / X=0)}}
$$

For Poisson's regression model, the relative risk is given by:

$$
R R_{X}=e^{\beta X} \text { Results }
$$

During the study period, there were 5850 hospitalizations for asthma in individuals from 0 to 10 years old living in Campo Grande. The daily average was 5.34 hospitalizations $(\mathrm{SD}=1.89)$, ranging from 2 to 13. Mean values with their standard deviations, minimum and maximum values are shown in Table 1 and Figures 1 and 2.

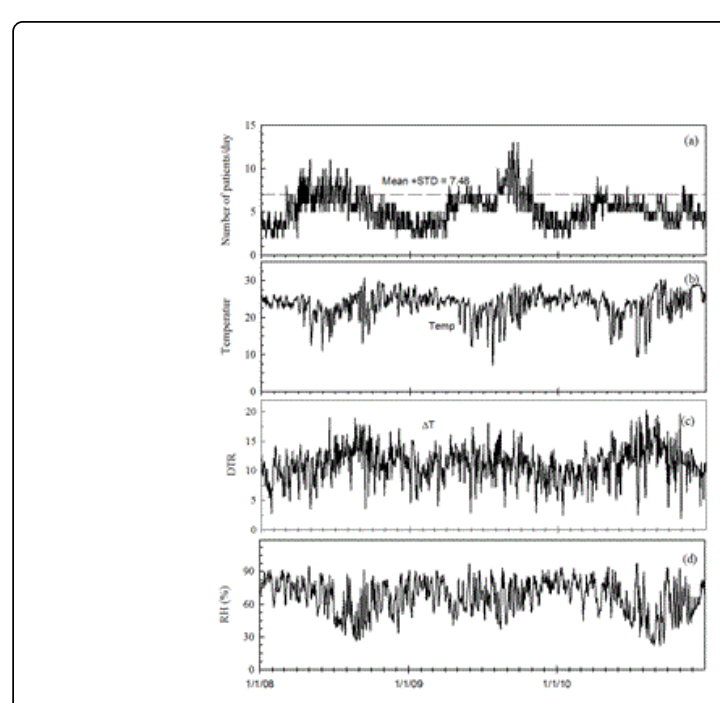

Figure 1: Number of hospital admissions, temperature and variation of temperature and wind speed, precipitation and concentration of ozone in function of days. Number of hospital admissions, temperature, temperature variation and relative humidity in the light of day.

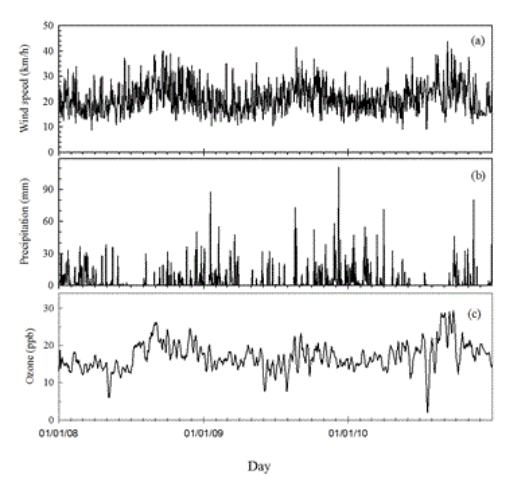

Figure 2: Wind speed, precipitation and in function of days.

The months with higher admissions numbers were April, May and June in the years of study, with correlations of 0.70 with the temperature; 0.99 with the relative humidity of the air; 0:15 with the speed of the wind and 0.79 with the concentration of ozone.

From Poisson's regression, having the parameters analyzed together, adjusted to temperature variations, humidity, wind speed, concentration of ozone and precipitation controlled by day of the week and seasonality, relative risks were obtained and their respective confidence interval for each parameter: ozone-RR 0.9965 (0.9467-1.0463); precipitation RR-0.9975 (0.9476-1.0474); RH RR-0.9948 (0.9450-1.0455); RR-speed winds 1.0036 (0.9535-1.0538) and RR-temperature 0.9679 (0.9195-1.0163).

Despite the small magnitude of the RR found, the impact of parameters on public health should be substantial, considering the 
Page 3 of 5

large number of exposed individuals. The results presented represent a quantitative approach to the climate impact/pollution on population health. More importantly, the outcome studied here, hospitalization, is just one of many effects caused by climatic variation.

\begin{tabular}{|l|l|l|l|l|l|l|}
\hline & Asthma & Temperature ${ }^{\circ} \mathbf{C}$ & Humidity $(\%)$ & Speed $(\mathbf{m} / \mathbf{s})$ & Precipitation $(\mathbf{m m})$ & Ozone $(\mathbf{p p b})$ \\
\hline Average Value & 5.34 & 29.95 & 82.75 & 21.22 & 3.87 & 17.05 \\
\hline S. deviation & 1.89 & 3.8 & 14.69 & 5.82 & 10.23 & 3.62 \\
\hline Total number & 1096 & 1096 & 1096 & 1096 & 1096 & 1096 \\
\hline Maximum & 13 & 38.3 & 98 & 43.56 & 111 & 29.29 \\
\hline Minimum & 2 & 10.9 & 30 & 8.64 & 0 & 2 \\
\hline
\end{tabular}

Table 1: Descriptive statistics of the number of hospitalizations for asthma, temperature $\left({ }^{\circ} \mathrm{C}\right)$, relative humidity $(\%)$ wind speed $(\mathrm{km} / \mathrm{h})$ and ozone concentration.

\section{Superposition analysis of weather parameters and ozone}

In this section, we focus on the year 2008 and perform superposed epoch analyses to study the behavior of diurnal temperature range (DTR), wind speed (V) and temperature (T), relative humidity (R.H), precipitation (pre) and ozone concentration for days with a high number of patients during 2008. To construct the superposed epoch we first define the day with a high number of patients as the day with number that exceeds the average number of patients during the entire year plus the associated standard deviation $(5.46+2.02)$. We obtain 97 days in 2008 with the number of asthmatic patients $\geq 7$. This number is considered as a lower limit of the number of patients and is represented by the dashed horizontal lines in Figure 1. We see that the numbers of patients above the dashed lines are mainly in April-August, when the temperature and R.H were low and the DTR $(\Delta T)$ is high. DTR is the difference between the daily maximum and minimum temperature. Next we consider these 97 days as key-event days. We first perform the superposition analysis on DTR. We arranged the daily values of the DTR for the key-event days (97 days) and background days (269 days) in a table, with one row for each key-event, and eleven columns containing values of DTR for the 5 days before the key-event day, the key-event day, and the subsequent 5 days, in that order. The values of these eleven averages are plotted in Figure 3a. Error estimates $(1 \pm \sigma)$ of the average for each column of the 11 epoch columns are calculated from the scatter of the individual deviation. We see any an increase in the average values of $\Delta \mathrm{T}$ on the days with higher patient numbers (the zero-epoch day when the number of patients $\geq 7$ ). It reaches a minimum two days after the zero-day. Similar calculations have been carried out for the rest of the weather parameters and ozone displayed in Figure 2. We compare between the average values of these parameters on the key-event column and background ten columns. Figure 3a shows an increase in the average values of ozone one the zero-day. It reaches maximum two days after the zero-day. We see a significant increase of wind speed on the zero-day of Figure $3 \mathrm{~b}$. Figure $3 \mathrm{c}$ shows an increase in temperature and decrease of R.H on the days with high patient numbers (zero-day).

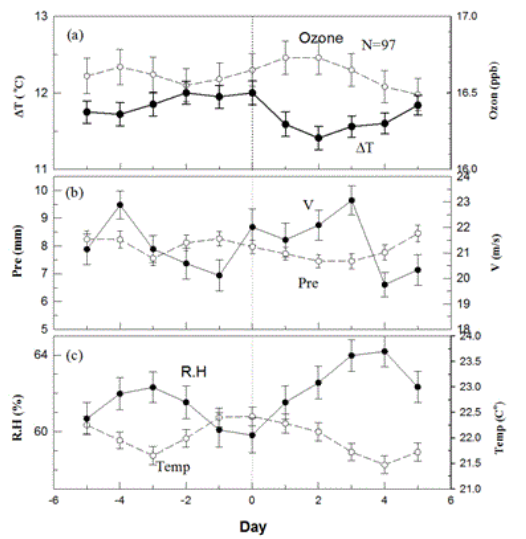

Figure 3: Changes in temperature, precipitation, relative humidity, concentration of ozone, wind speed and temperature as a function of days. Superposed weather parameters centered on the 97 days with the number of asthmatic patients $\geq 7$. Error bars represent the standard error in each average.

\section{Discussion}

During the study period, it was found that hospitalizations for asthma in children up to 10 years, showed a positive and insignificant association with ozone, with a relative risk of 0.9965 .

The increase in wind speed helps to spread the pollens in air and consequently increase the number of patients. The increase in relative humidity may trigger asthmatic symptoms. In general not found direct association between the number of asthmatic patients and levels of air pollutants or dust storms. Sabbah et al. [22].

In a search of Gouveia et al. [23], held in São Paulo, Brazil, it was observed that an increase of $10 \mathrm{ug} / \mathrm{m}^{3}$ in the level of inhalable particulate matter is associated with the increase of $4.6 \%$ in hospitalizations for asthma in children.

A survey conducted by Bakonyi et al. [2] showed a statistically significant effect for ozone only on the moving average of three days. 
This statistical difference may exist due to the fact that the study variable were individuals 0 -14 years old, treated for all respiratory causes, not just asthma, and also to the fact that we used moving averages, not lag, as in the present study.

The maximum daily concentration of pollutant was $104 \mathrm{ug} / \mathrm{m}^{3}$, with an average of $80 \mathrm{ug} / \mathrm{m}^{3}$ during the period from 2008 to 2010 . The World Health Organization Manual accepted the level of maximum exposure up to $100 \mathrm{mg} / \mathrm{m}^{3}$ for 8 hours, for 1 day [24]. Levels above 240 $\mathrm{mg} / \mathrm{m}^{3}$ are associated with significant health effects such as decreased lung function, inflammation and hyperreactivity of the respiratory tract.

In São Paulo, it was observed between 1996 and 2000, an average ozone of $71.79 \mathrm{ug} / \mathrm{m}^{3}$ [23]. In other research, conducted in the cities of Curitiba and Rio de Janeiro, the average values of $\mathrm{O} 3$ were $63.71 \mathrm{ug} / \mathrm{m}^{3}$ and $81.08 \mathrm{ug} / \mathrm{m}^{3}[2,25]$.

De Souza et al. [3] studied the $\mathrm{O}_{3}$ effect on respiratory morbidity, there was a delay of two to four days to have a statistically significant effect on hospital admissions for all age groups, except for those aged between 5-60 years old. Children and the elderly were more vulnerable to ozone pollution than people aged 5-60 years old. In urban areas, exposure to air pollutants is characterized by long periods and low levels of pollutants [26], unlike air pollution originating from bonfire, whose main characteristic is the well-defined seasonality and high levels mainly particulate matter [27].

Burning biomass, as the results of Piracicaba (SP) and the Amazon region, has an important role in the concentrations of pollutants [28-31]. Despite the small magnitude of RR found, the impact of air pollution on public health should be substantial, considering the large number of exposed individuals. The results presented a quantitative approach to the impact of air pollution on health.

The outcome studied, hospitalization, is just one from many effects caused by air pollution. Effects such as the occurrence of symptoms, medication use, school absenteeism and reduced physical activity, etc., are not evaluated in this study. These are considered minor to an individual's health are very important to public health because of the high frequency of occurrence and the negative impact on quality of life and negative economic consequences such as absenteeism at school and at job.

Souza et al. [32] studied that the pollutant, ozone, was significantly associated with respiratory admissions. An increase of $5.3 \mathrm{ppb}$. In the ozone concentration level is associated with $10 \%$ of increase in hospitalizations for respiratory diseases. These associations between increased level of pollutants in the atmosphere and increased hospitalizations are in accordance with national and international literature about the subject and indicate that current levels of air pollution in Campo Grande have impact on the health of its population.

Most children with asthma in Latin America are not atopic, some important risk factors are poverty, including poor hygiene (i.e., dirt), poor diet and obesity and psychosocial stress. There is evidence that exposure to infections during childhood reduce atopy, but not asthma. A research is needed to identify the causes of non-atopic asthma that may be suitable for primary prevention, or other public health intervention strategies for asthma in Latin America [33].

Many time-series studies have found that hospitalizations or emergency room visits due to asthma may increase in the short-term periods of exposure to high ozone levels [34-37]. Other studies assessed the risk of asthma hospitalizations in children associated with chronic exposure to ozone. The results of this study are consistent with several previous studies among children. Three cross-sectional studies have observed a positive relation between chronic exposure to ozone, and the prevalence of asthma and asthma symptoms in school-age children $[38,39]$ reported a decrease in lung function associated with a higher concentration of ozone between school-age children in two prospective studies. Concentration of ozone is associated with hospitalization for asthma during childhood in Hong Kong [40].

This study uses secondary data to calculate the ratios and relative risks for hospitalizations resulting from the high level of air pollution/ climatic variables observed. These data come from stable and very reliable sources, widely used in technical and scientific papers. The records refer to hospitalizations occurring in health services offered by the government. Thus, the results presented here reflect the effects of air pollution on the part of the population that uses this service, which is the largest part of the population.

On the other hand, SUS Hospital Information System data used in this study are gotten with financial objectives, and not strictly for epidemiological studies, and it can provide some degree of inaccuracy. There may have been some degree of underestimation of the frequency of certain health problems, due to the technological characteristics of the service network, and errors in the diagnoses encoding.

The article was not subject to approval by the Ethics Committee, because the data secondary and the risks are minimal. Considering it is secondary data the ethical aspects of research involving human beings were respected, in accordance with Resolution Number 466/2012 [41] on the maintenance of sigil.

This study shows that even population from mid-sized cities can be affected by environmental pollution, reflecting increasing incidence of hospitalizations for asthma and low life quality of citizens.

\section{Conclusion}

Short-term exposure to climatic parameters confers an increased risk of asthma-related to hospital admissions. Our findings call for greater awareness of environmental protection and the implementation of effective measures to improve quality of life, which may reduce the risks of adverse effects on the population's health. However, the effects need to be interpreted cautiously since longer lags are essential in timeseries studies to better determine the effects of climatic parameters on asthma outcomes.

The health professional must recognize the importance of the effects of pollutants in clinical practice and properly assess the patients' exposure profile at their homes, workplaces and regions where they live. If you cannot reduce the emission of short or medium term pollutants, it is perfectly possible to guide patients to adopt preventive measure that seek for reducing effects of pollutants in external and internal environments, reducing the adverse effects related to such exposure.

\section{References}

1. Bakonyi SM, Danni-Oliveira IM, Martins LC, Braga AL (2004) Air pollution and respiratory diseases among children in the city of Curitiba, Brazil. Rev Saude Publica 38: 695-700.

2. Gouveia N, Mendonça GAS, Leon AP, Correia JEM, Junger WL, et al. (2003) Poluição do ar e efeitos na saúde nas populações de grandes metrópoles brasileiras. Epidemiol Serv Saúde 12: 29- 40. 
Page 5 of 5

3. de Souza A, Guo Y, Pavão HG, Fernandes WA (2014) Effects of Air Pollution on Disease Respiratory: Structures Lag. Health 6: 1333-1339.

4. Kim JJ, American Academy of Pediatrics Committee on Environmental Health (2004) Ambient air pollution: health hazards to children. Pediatrics 114: 1699-1707.

5. Brauer M, Hoek G, Smit HA, de Jongste JC, Gerritsen J, et al. (2007) Air pollution and development of asthma, allergy and infections in a birth cohort. Eur Respir J 29: 879-888.

6. Gauderman WJ, Avol E, Gilliland F, Vora H, Thomas D, et al. (2004) The effect of air pollution on lung development from 10 to 18 years of age. $\mathrm{N}$ Engl J Med 351: 1057-1067.

7. Nascimento LF, Pereira LA, Braga AL, Módolo MC, Carvalho JA Jr (2006) Effects of air pollution on children's health in a city in Southeastern Brazil. Rev Saude Publica 40: 77-82.

8. Hiltermann TJ, Stolk J, van der Zee SC, Brunekreef B, de Bruijne CR, et al. (1998) Asthma severity and susceptibility to air pollution. Eur Respir J 11: 686-693.

9. Committee of the Environmental and Occupational Health Assembly of the American Thoracic Society (1996) Health effects of outdoor air pollution. Am J Respir Crit Care Med. 153: 3-50.

10. Mascarenhas MD, Vieira LC, Lanzieri TM, Leal AP, Duarte AF, et al (2008) Anthropogenic air pollution and respiratory disease-related emergency room visits in Rio Branco, Brazil--September, 2005. J Bras Pneumol 34: 42-46.

11. Prietsch SO, Fischer GB, César JA, Cervo PV, Sangaletti LL, et al. (2006) Risk factors for recurrent wheezing in children under 13 years old in the South of Brazil. Rev Panam Salud Publica 20: 331-337.

12. Brasil. Portal da Saúde. SUS. Asma grave. Disponível em.

13. Souza A, Schujmann E, Fachel JMG, Fernandes WA (2013) Environmental indicators and respiratory diseases in children Mercator Fortaleza 12: 101-109.

14. Brasil. Departamento de Informações e Informática do Sistema Único de Saúde, DATASUS]. Disponível em.

15. Braga ALF, Saldiva PHN, Pereira LAA, Menezes JJC, Conceição GMS (2001) Health effects of air pollution exposure on children and adolescents in São Paulo, Brazil. Pediatric Pulmonology 31: 106-113.

16. Martins LC, Latorre Mdo R, Cardoso MR, Goncalves FL, Saldiva PH, et al. (2002) Air pollution and emergency room visits due to pneumonia and influenza in São Paulo, Brazil. Rev Saude Publica 36: 88-94.

17. Freitas C, Bremner SA, Gouveia N, Pereira LA, Saldiva PH (2004) Hospital admissions and mortality: association with air pollution in São Paulo, Brazil, 1993 to 1997. Rev Saude Publica 38: 751-757.

18. Tadano YS, Ugaya CML, Franco AT (2009) Methodology to assess air pollution impact on the population's health using the Poisson regression method. Ambiente \& Sociedade 12: 241-255.

19. Dobson AJ, Barnett AG (2008) An introduction to generalized linear models. 3rd edn. Chapman \& Hall, Florida, USA, p: 320.

20. Everitt BS (2003) Modern medical statistics. New York, USA: Oxford University Press Inc, p: 235.

21. Baxter LA, Finch SJ, Lipfert FW, Yu Q (1997) Comparing estimates of the effects of air pollution on human mortality obtained using different regression methodologies. Risk Anal 17: 273-278.

22. Sabbah I, Arifhodzic N, Al-Ahmad MS, Al-Enizi A, Al-Haddad A, et al (2014) Influence of Air Quality Conditions on Asthmatic Patient Visits in Kuwait. J Allergy Ther 5: 197.

23. Gouveia N, de Freitas CU, Martins LC, Marcilio IO (2006) Respiratory and cardiovascular hospitalizations associated with air pollution in the city of São Paulo, Brazil. Cad Saude Publica 22: 2669-2677.
24. Organização Mundial da Saúde. Air Quality Guideline. Disponível em

25. Castro HA, Cunha MF, Mendonça GAS, Junger WL, Cunha-Cruz J (2009) Efeitos da poluição do ar na função respiratória de escolares, Rio de Janeiro, RJ. Rev Saúde Pública 43: 26-34.

26. Gouveia N, Fletcher T (2000) Respiratory diseases in children and outdoor air pollution in São Paulo, Brazil: a time series analysis. Occup Environ Med 57: 477-483.

27. Amâncio CT, Nascimento LF (2012) Asthma and ambient pollutants: a time series study. Rev Assoc Med Bras 58: 302-307.

28. Silva AM, Mattos IE, Ignotti E, Hacon Sde S (2013) Particulate matter originating from biomass burning and respiratory. Rev Saude Publica 47: 345-352.

29. Andrade Filho VS, Artaxo P, Hacon S, Carmo CN, Cirino G (2013) Aerosols from biomass burning and respiratory diseases in children, Manaus, Northern Brazil. Rev Saude Publica 47: 239-247.

30. Ignotti E, Valente JG, Longo KM, Freitas SR, Hacon Sde S, et al. (2010) Impact on human health of particulate matter emitted from burnings in the Brazilian Amazon region. Rev Saude Publica 44: 121-130.

31. Cesar AC, Nascimento LF, Carvalho Jr JA (2013) Association between exposure to particulate matter and hospital admissions for respiratory disease in children. Rev Saude Publica 47: 1209-1212.

32. Souza A, Pavão HG, Lastoria G, Gabas SG, Paranhos Filho AC, Cavazzana GH (2010) Hospitalizações por causas respiratórias associadas à poluição atmosférica em Campo Grande, MS. Revista Biociências, Unitau 16: 1 .

33. Cooper PJ, Rodrigues LC, Barreto ML (2012) Influence of poverty and infection on asthma in Latin America. Curr Opin Allergy Clin Immunol 12: $171-178$.

34. Zheng XY, Ding H, Jiang LN, Chen SW, Zheng JP, et al. (2015) Association between Air Pollutants and Asthma Emergency Room Visits and Hospital Admissions in Time Series Studies: A Systematic Review and Meta-Analysis. PLoS One 10: e0138146.

35. Restrepo C, Simonoff J, Thurston G, Zimmerman R (2012) Asthma Hospital Admissions and Ambient Air Pollutant Concentrations in New York Journal of Environmental Protection 3: 1102-1116.

36. Lin S, Liu X, Le LH, Hwang SA (2008) Chronic exposure to ambient ozone and asthma hospital admissions among children. Environ Health Perspect 116: 1725-1730.

37. Gent JF, Triche EW, Holford TR, Belanger K, Bracken MB, et al. (2003) Association of low-level ozone and fine particles with respiratory symptoms in children with asthma. JAMA 290: 1859-1867.

38. Hwang BF, Lee YL, Lin YC, Jaakkola JJ, Guo YL (2005) Traffic related air pollution as a determinant of asthma among Taiwanese school children. Thorax 60: 467-473.

39. Rojas-Martinez R, Perez-Padilla R, Olaiz-Fernandez G, MendozaAlvarado L, Moreno-Macias H, et al. (2007) Lung function growth in children with long-term exposure to air pollutants in Mexico City. Am J Respir Crit Care Med 176: 377-384.

40. Lee SL, Wong WH, Lau YL (2006) Association between air pollution and asthma admission among children in Hong Kong. Clin Exp Allergy 36: 1138-1146.

41. BRASIL. Portaria $\mathrm{n}^{\circ} 466 / 2012$ de outubro de 2012. Dispõe sobre diretrizese normas regulamentadoras de pesquisa com seres humanos. Brasília (DF): Conselho Nacional de Saúde; 2012. Publicada no Diário Oficial da União de 13 de junho de 2013, Seção 1, p: 59. 